\title{
EFFECTIVE UTILISATION OF WASTE MATERIALS ON CONCRETE
}

\author{
R. Ram Kumar ${ }^{1}$, B. Jose Ravindraraj ${ }^{2}$, A. Babu ${ }^{3}$, R. Saranya ${ }^{4}$ \\ ${ }^{1}$ PG Scholar, Structural Engineering, PRIST University Thanjavur, Tamil Nadu, India. \\ ${ }^{2}$ Assistant Professor, Civil Engineering, PRIST University Thanjavur, Tamil Nadu, India. \\ ${ }^{3} P G$ Scholar, Structural Engineering, PRIST University Thanjavur, Tamil Nadu, India. \\ ${ }^{4}$ PG Scholar, Structural Engineering, PRIST University Thanjavur, Tamil Nadu, India.
}

\begin{abstract}
In the world, concrete is material which is produced more than any other man made material. Due to the increasing of population in the world, a waste material also increases. In those waste materials many are non-degradable materials, they make hazards to the environment.So, that usage of non degradable waste [1] in concrete will be safe for disposal. This project will give the ideas, experimental analysis of the recycled aggregates (Coarse Aggregates) and waste glass materials (Fine aggregates) on the concrete mix. Desired properties of concrete such as strength, workability,durability can also achieved by adding above materials in the concrete.
\end{abstract}

Keywords: Recycled Aggregate, Powder of Waste Glass, Coarse Aggregate-Partial Replacement, Fine Aggregate, Compression Test, Flexural Strength, Split Tensile Test.

\section{INTRODUCTION}

In the world, concrete is material which is produced more than any other man made material. Due to the increasing of population in the world, a waste material also increases. In those waste materials many are non- degradable materials, they make hazards to the environment. This may lead to environmental hazards like soil pollution [1]. By the hazards of soil pollution agricultural lands gets affected. Agriculture is the good economy of India. To resolve this kind of issues occurs now a day's substitutes need to be finded out.

In the field of construction and engineering the waste are used. Likewise non-Degradable wastes such as waste glasses, recycled aggregates are going to be used in this project with the concrete. The waste glasses are such as container glass, window glass, Bulb glass etc... can be used with the concrete. Our country India also stands in a position of more usage of glass materials. Some waste glass is again recycled as glasses and more wastes of glass are dumped as landfill. This kind of disposal of waste creates hazards to the environment and also to the peoples there. So, that usage of non degradable waste in concrete will be safe for disposal.

Now a day's building demolition is one of the major activities, waste from the demolishing activities is mostly dumped as land fill in the buildings. The crushed concrete debris can be used as coarse aggregates in the concrete mix [2]. Recycled aggregates from the demolished buildings can be used in the concrete. So, that cost of construction can also be reduced. This project will give the ideas, experimental analysis of the recycled aggregates (Coarse Aggregates) and waste glass materials (Fine aggregates) on the concrete mix.

Throughout the field, concrete is being widely used for the construction of most of the bridges, buildings etc. Currently, the entire construction industry is in search of effective and suitable waste product that would considerably minimize the use of cement aggregates and ultimately reduces the construction cost. Such a alternative materials are recycled aggregates and waste glass materials [1]. Most of recycled aggregates and waste glass materials are dumped in landfills without any pretreatment because it is traditionally useless and ultimately creates serious eco problems. Therefore, proper alternate is required to manage the wastes in ecofriendly way.

In this project an attempt has been made to use recycled aggregates and waste glass materials as a partial replacement of fine aggregate and coarse aggregates [3]. Recycled aggregates is replaced by $2.5 \%, 5 \%$ and $7.5 \%$ in addition with the waste glass materials by $5 \%, 10 \%, 15 \%$ of weight of aggregates. The strength characteristics such as compressive strength, tensile strength of recycled aggregates and waste glass materials based concrete were investigated.

\section{MATERIALS USED}

\subsection{Cement}

Cement is a well-known building material and has occupied an indispensable place in construction work. There is a variety of cement available in market and each type is used under certain condition due to its special properties such as color and composition of cement. The function of cement is, first to bind the sand and coarse aggregates together, and second to fill the voids. Although cement constitutes only about 10 percentage of the volume of the concrete mix, it is the active portion of the binding medium and the only scientifically controlled ingredient of concrete.

Ordinary Portland cement is the most common type of cement used. The commonly used Portland cement in India 
is branded as 33-grade (IS 269-1989), 43-grade (IS 81121989) and 53-grade (IS 12269-1987) having 28 days mean compressive strengths $33 \mathrm{MPa}, 43 \mathrm{MPa}$, and $53 \mathrm{MPa}$ respectively.

\section{2 Fine Aggregate (Sand)}

Sand which passes through $4.75 \mathrm{~mm}$ IS sieve and contains only that much of coarser material as is permitted by the specifications. Sand is generally considered to have a lower size limit of about $0.07 \mathrm{~mm}$. According to size, the sand may be described as coarse, medium and fine sands. Depending upon the particle size distributions IS 383-1970 [4] has divided the fine aggregate into four grading zones. The grading zones progressivelybecome finer from grading zone 1 to grading zone 4 . Locally available river sand of grading zone I confirming to IS 383-1970 (BIS, 1970) [4] was used in this experimental work.

\subsection{Coarse Aggregate (Gravel)}

Gravel which is above the size of $4.75 \mathrm{~mm}$ IS sieve. The coarse aggregate is chosen angular and sharper to have good binding nature with the concrete. The coarse aggregate used in this experimental analysis is $12 \mathrm{~mm}$ angular conforming to IS 383-1970 (BIS, 1970).

\subsection{Waste Glass Powder (Partial Replacement For}

\section{Fine Aggregate)}

The waste glasses are collected from the beverages factories, damaged windows, doors, wine shops,etc...The waste containers, glasses are cleaned ,crushed and sieving process are done for the usage of waste in the concrete mix. The separation of the crushed waste powder is done according to size distribution. The process behind is illustrated by figure.

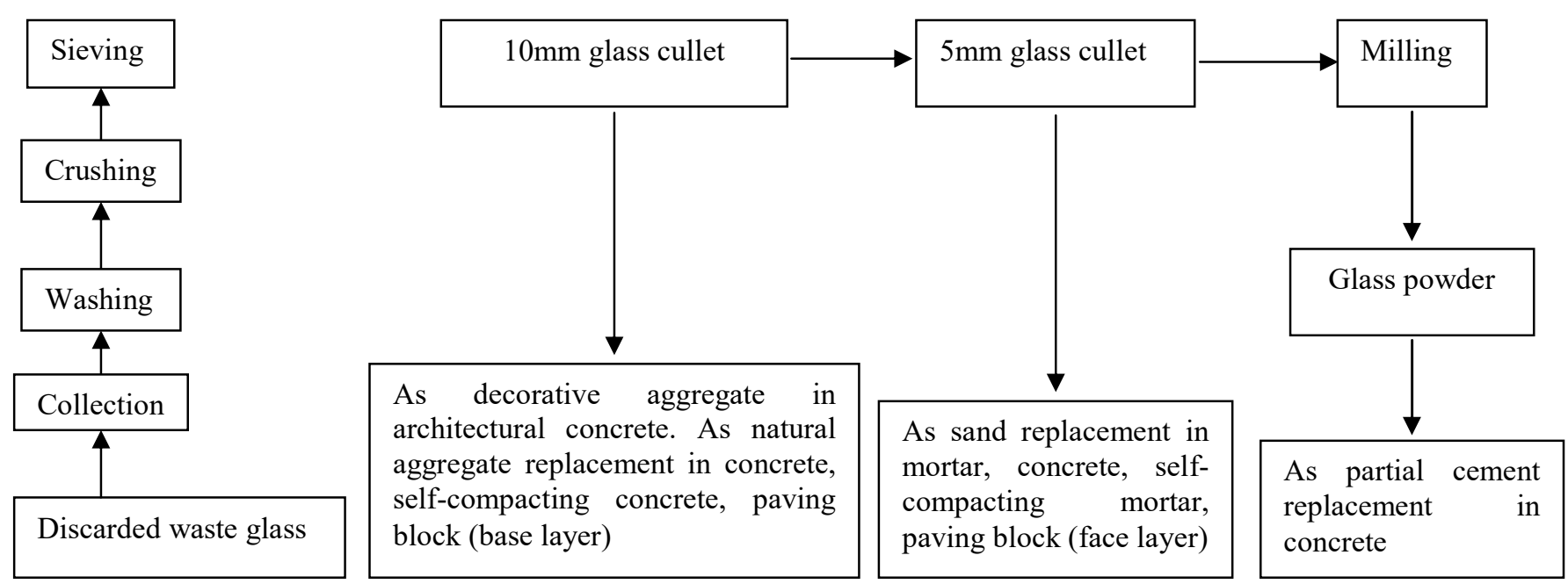

Figure- 1 Process of separating waste glass

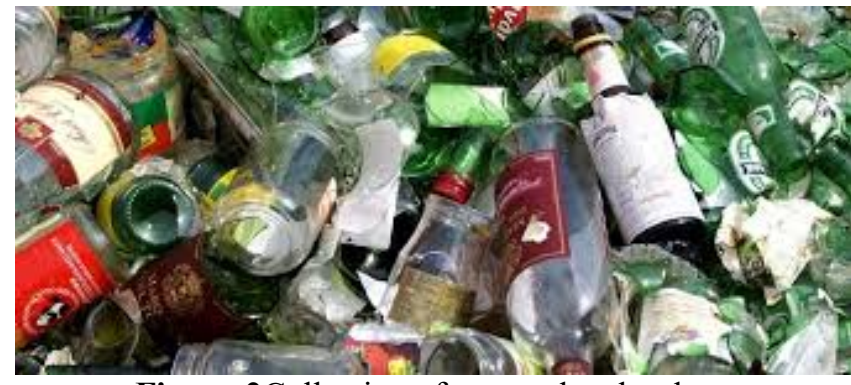

Figure-2Collection of waste glass bottles

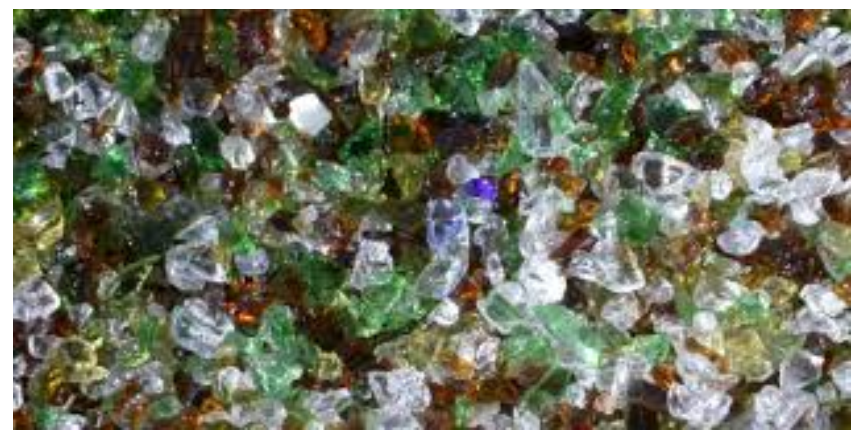

Figure-3 Crushed waste glass

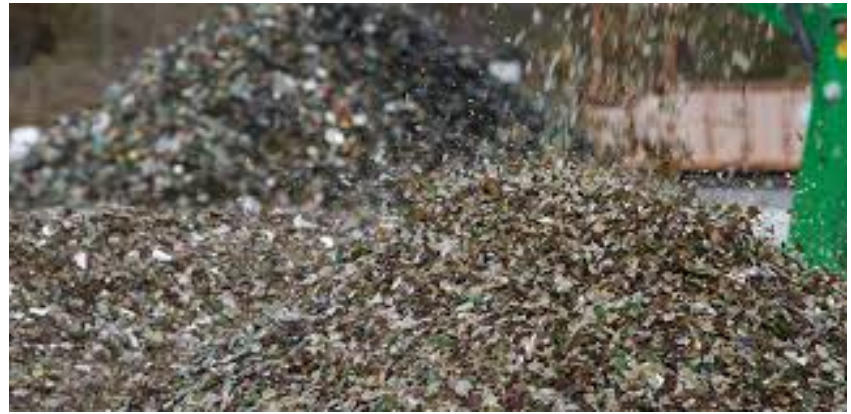

Figure-4 Powdered waste glass (Partial replacement for fine aggregate).

\subsection{Recycled Aggregates}

The waste from the demolition of concrete structures are collected, aggregates are separated as recycled aggregates. The proposed recycled aggregates are used in the concrete mix for this project. The recycled aggregates are conformed by means of grading. As per specification $12 \mathrm{~mm}$ angular recycled aggregates are selected for partial replacement. 


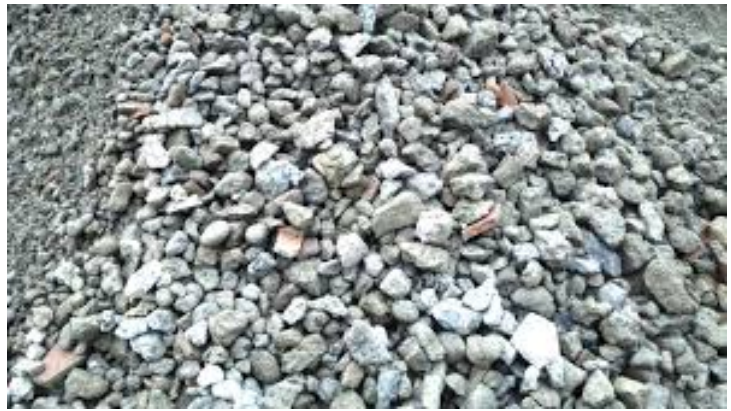

Figure-5 demolished concrete

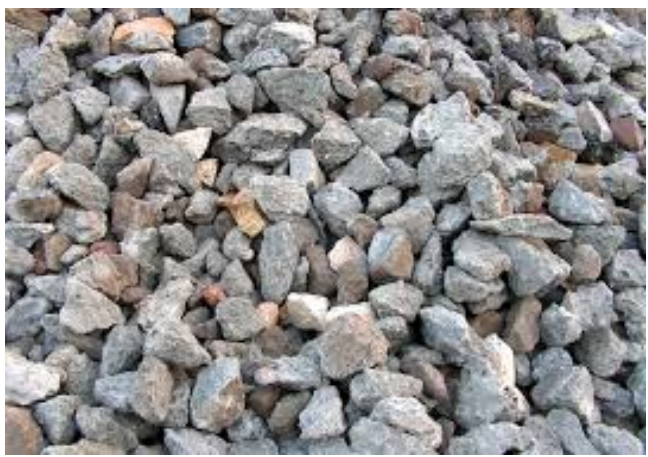

Figure- 6 Recycled Aggregate

\section{MIX PORPORTION}

The grade of concrete chosen for experimental analysis is $\mathrm{M}_{30}$. By conforming to Is 10262 [5]\& IS 456: 2000 [6] concrete is designed and proportions were detected. Actual proportions detected by designing are for $1 \mathrm{~kg}$ of cement, $1.73 \mathrm{~kg}$ of fine aggregate, $2.94 \mathrm{~kg}$ of coarse aggregate. By this above results partial replacement in fine aggregate and coarse aggregates are made. The partial replacement is made for fine aggregate with waste glass powder by increasing with $5 \%, 10 \%$, and $15 \%$ of weight of fine aggregates. The partial replacement is made for the coarse aggregate with recycled aggregates by increasing with $2.5 \%, 5 \%$ and $7.5 \%$ of weight of coarse aggregates.

\begin{tabular}{|l|l|l|}
\hline $\begin{array}{l}\text { MIX } \\
\text { COMBINATION }\end{array}$ & $\begin{array}{l}\text { Waste glass(\%) } \\
\text { Replacement of } \\
\text { fine aggregate }\end{array}$ & $\begin{array}{l}\text { Recycled } \\
\text { Aggregate(\%) } \\
\text { Replacement } \\
\text { coarse aggregate }\end{array}$ \\
\hline CONTROL & 0 & 0 \\
\hline W5 R0 & 5 & 0 \\
\hline W10 R0 & 10 & 0 \\
\hline W15 R0 & 15 & 0 \\
\hline W5 R2.5 & 5 & 2.5 \\
\hline W5 R5 & 5 & 5 \\
\hline W5 R7.5 & 5 & 7.5 \\
\hline W10 R2.5 & 10 & 2.5 \\
\hline W10 R5 & 10 & 5 \\
\hline W10 R7.5 & 10 & 7.5 \\
\hline W15 R2.5 & 15 & 2.5 \\
\hline W15 R5 & 15 & 5 \\
\hline W15 R7.5 & 15 & 7.5 \\
\hline
\end{tabular}

\section{EXPERIMENTAL INVESTIGATION}

The fresh concrete tests such as compaction factor test and slump cone test were carried out to estimate the workability of concrete. The results of partially replaced concrete are compared with control concrete mix. The hardened concrete tests such as compression test, flexural strength test, and split tensile test were carried out to estimate the strength properties of concrete and compare the partial replaced concrete with control concrete [7].

The compression tests are carried out for all the desired partial mix. The partial mix with above $31.6 \mathrm{~N} / \mathrm{mm}^{2}$ i.e., above $\mathrm{f}_{\mathrm{ck}}$ are taken for the flexural strength test and split tensile test [9]. Then the results were compared with the control specimen results.

\section{TEST RESULTS OF SPECIMENS}

The specimens were carried out with the several tests like slump cone test, compaction factor test, compression test, flexural strength test, split tensile test. The above following test reports are furnished below.

\subsection{Slump Cone Test}

Workability of fresh concrete is determined by means of slump cone test. The slump cone test apparatus will contain slump cone and tamping rod. The fresh concrete is prepared and it is used for testing. Preliminarily, the cone is oiled than concrete is laid as four layers in cone and tamped by help of tamping rod for 25 times at every layer. The difference of height is called as slump of concrete.

The slump cone testvalues of partial mix are compared with the control mix of concrete. Comparison chart is furnished below.

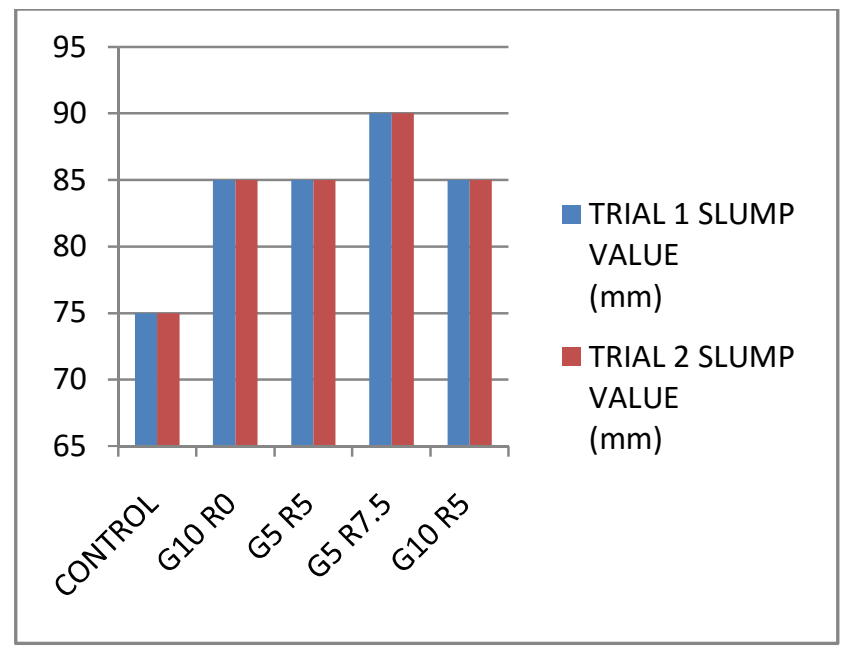

Chart -1 Comparison of partial mix with control mix (slump test)

\subsection{Compaction Factor Test}

Workability of fresh concrete is also detected by means of compaction factor test, they are done by compaction factor 
apparatus. The fresh concrete is prepared and they are laid in the top hopper of setup. The door is opened after filling at the top hopper, the concrete automatically falls on the lower hopper. The lower hopper door is opened, the concrete falls into the cylinder. The concrete which is excess in the cylinder is leveled by using the trowels. Then finally cylinder is filled with concrete and compacted fully. The cylinder with concrete weighed again. Compacting factor $=$ (partial concrete weight) $/$ (fully compacted concrete weight).

The compaction factor test values of partial mix are compared with the control mix of concrete. Comparison chart is furnished below.

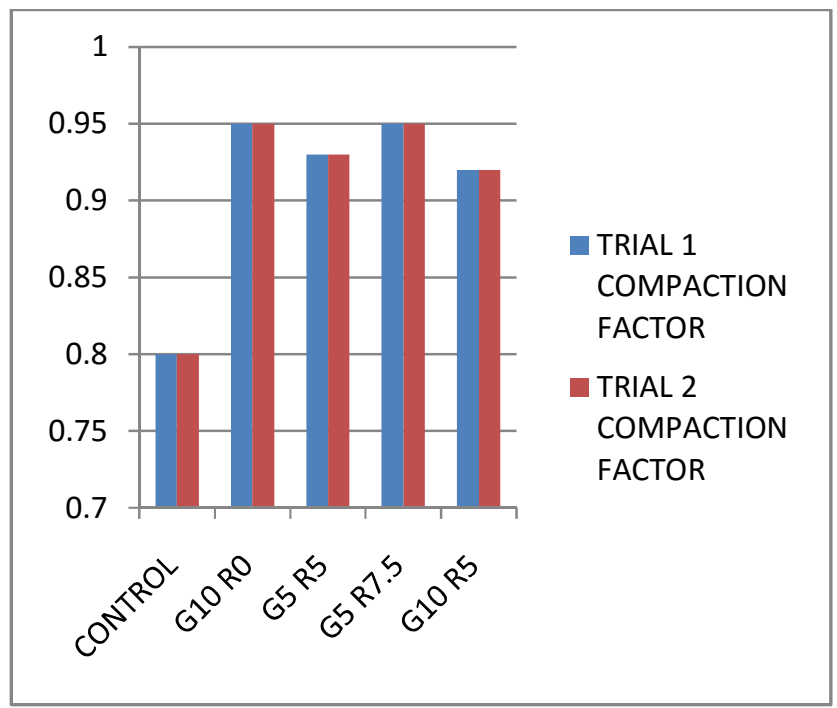

Chart -2 Comparison of partial mix with control mix (compaction factor test).

\subsection{Compression Test}

The compression test is used to estimate the compressive strength of concrete. It is one of the vital factors in concrete. The specimens used for the test of compression are $150 \times 150 \times 150 \mathrm{~mm}$ with partial mix proportions and with control mix. After 24 hours of time the specimens are deshuttered and they are allowed for curing for 28 days from day of casting. The compression strength of concrete is detected by means of compressive testing machine.

The concrete cubes were placed in the testing machine and load has gradually applied on the cubes. The ultimate load at which cube fails was taken and strength has calculated. The same manner was repeated to the cubes of other combinations. The compression tests values of partially mixed concrete specimens are compared with the values of control specimens. Thecomparison chart were furnished below for $7^{\text {th }}$ day, $14^{\text {th }}$ day,, $28^{\text {th }}$ day of specimens individually.

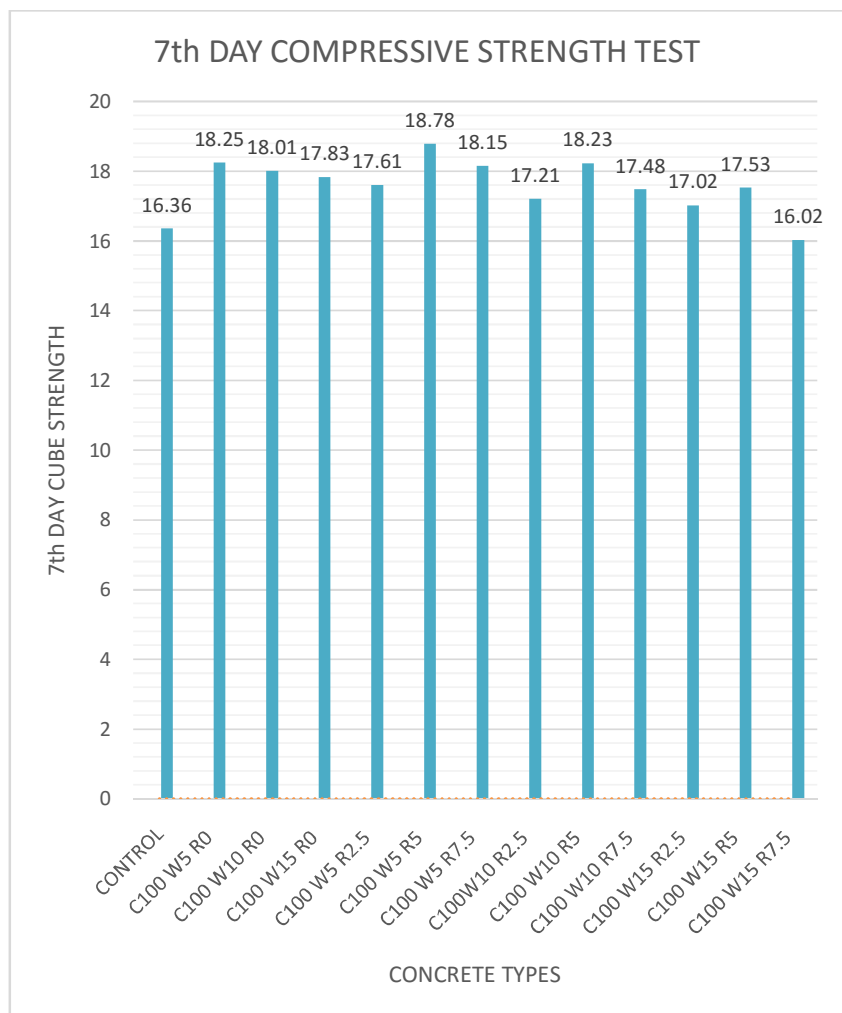

Chart -3 ( $7^{\text {th }}$ day compression test)comparison of partial mix specimens with control specimens.

14th DAY COMPRESSIVE STRENGTH TEST

30

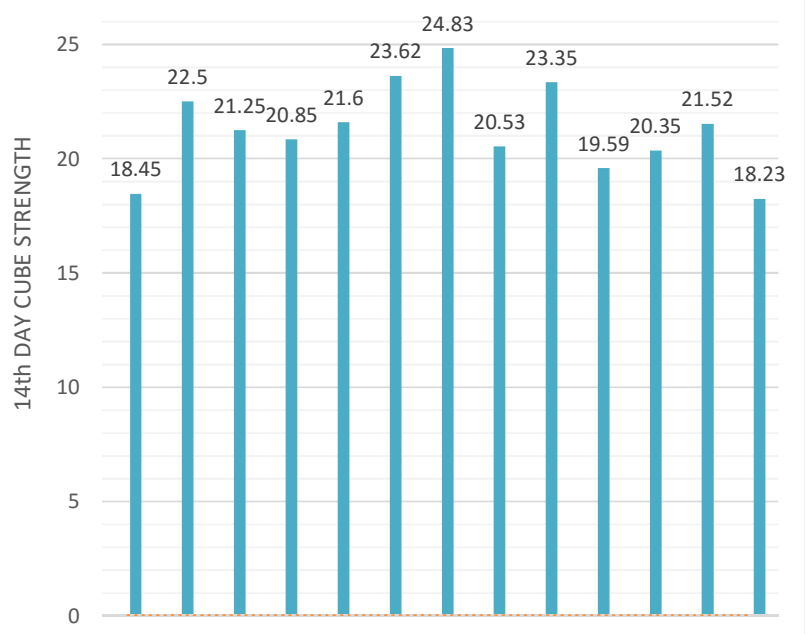

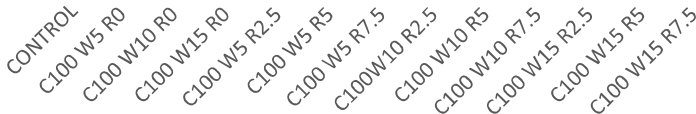

CONCRETE TYPES

Chart- 4(14 ${ }^{\text {th }}$ day compression test $)$ comparison of partial mix specimens with control specimens. 


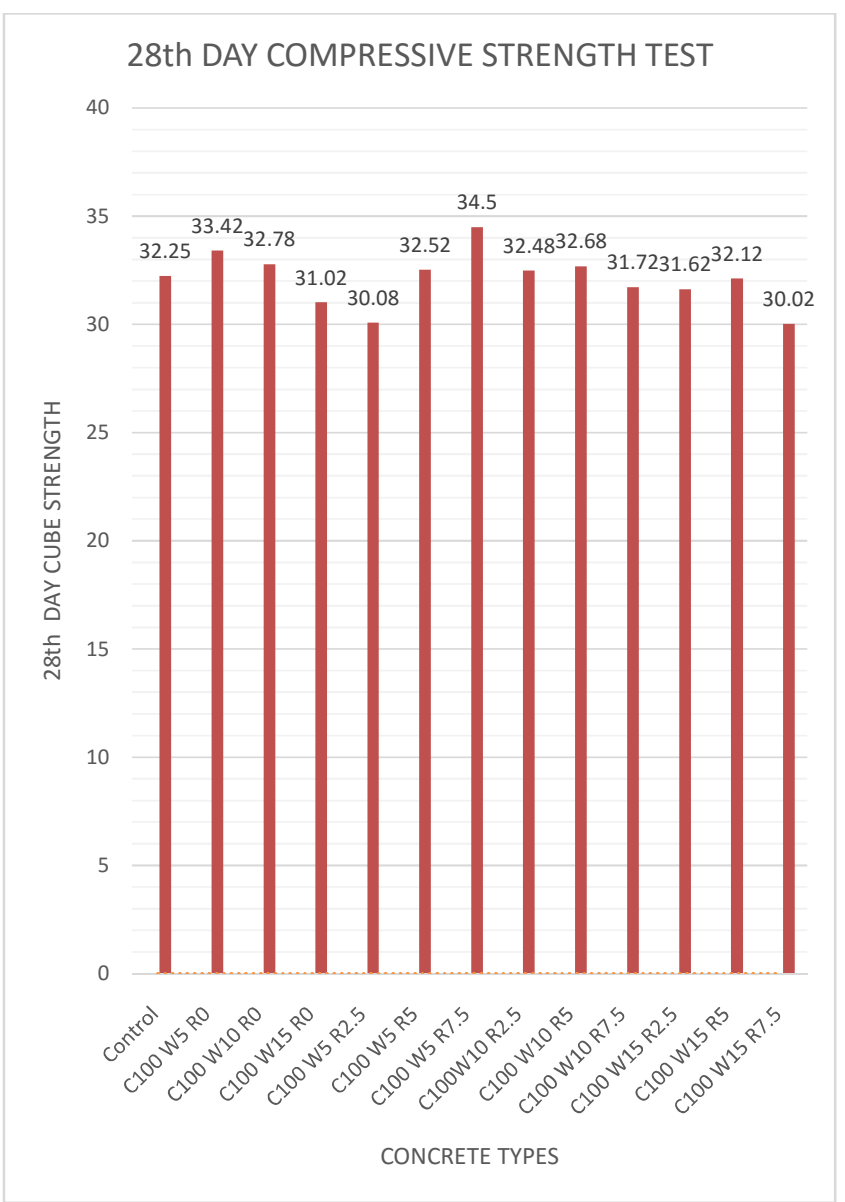

Chart- 5 ( $28^{\text {th }}$ day compression test) comparison of partial mix specimens with control specimens.

\subsection{Flexural Strength Test}

As we know concrete is good in compression and weak in tension. The tensile strength of concrete is analyzed. So, that by means of flexural strength test the tensile strength of concrete is estimated. It is the measure of unreinforced beam to resist failure in bending. In the flexural test of the specimen strength is expressed as stress. Specimen size of beam is $100 \times 100 \times 500 \mathrm{~mm}$. beam has casted and tested.

$$
F_{b}=P I / b d^{2}
$$

$\mathrm{P}$ - Applied load in $\mathrm{kN}$

1 - Beam length in $\mathrm{mm}$

$\mathrm{b}-$ Beam Width in $\mathrm{mm}$

$\mathrm{d}-$ Depth of the beam.

The flexural strength test is carried out for the partial mix specimens and controlled specimens. They are tested on $7^{\text {th }}$, $14^{\text {th }}, 28^{\text {th }}$ day from the day of casting. The charts were generated for the analysis of tensile strength of the partial mix specimens and control specimens.

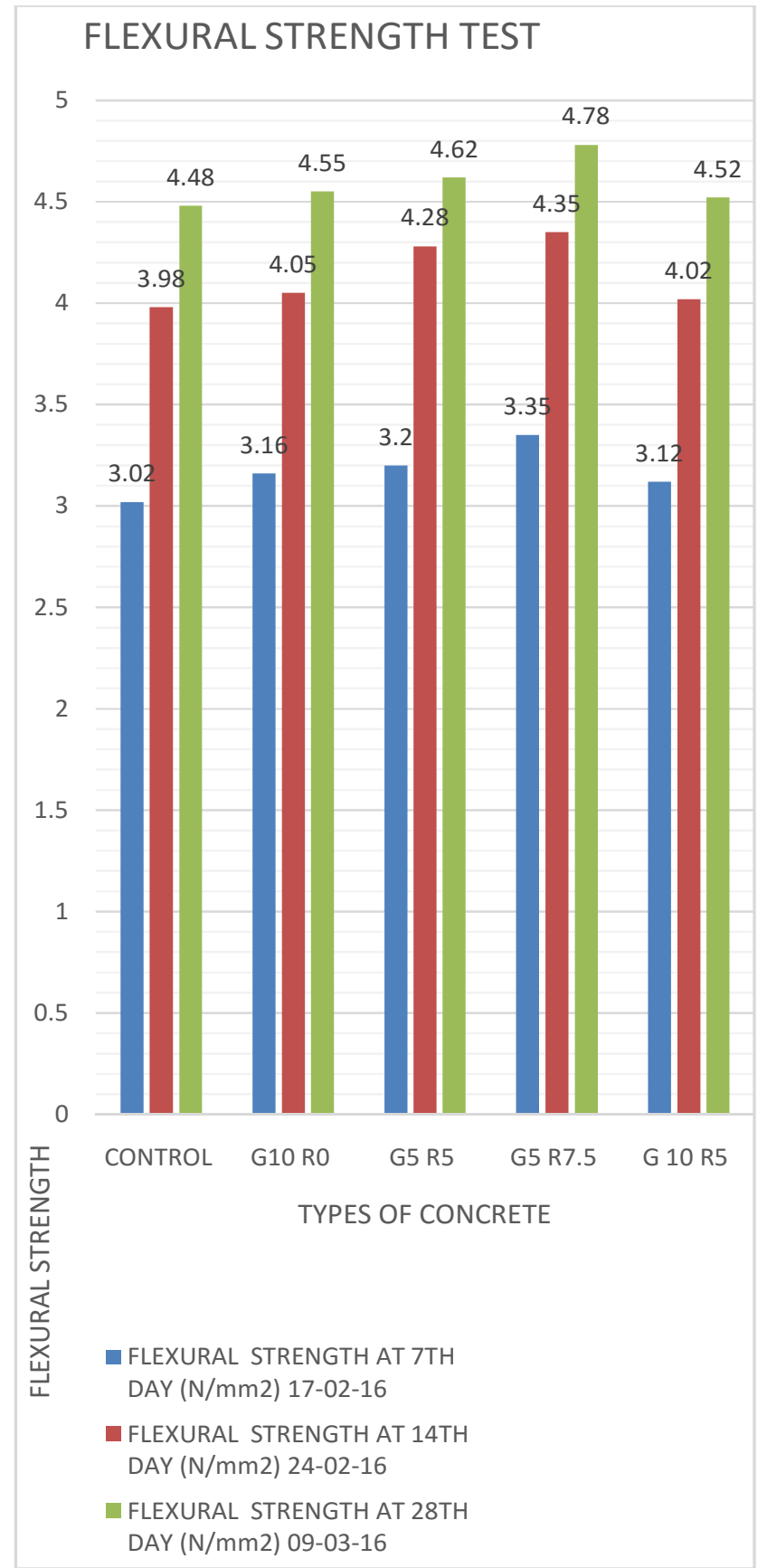

Chart - 6Comparison of flexural strength test for partial mix specimens and control specimens.

\subsection{Split Tensile Test}

The tensile strength is one of the basic and important properties of the concrete. Thetensile strength of concretedetermination is necessary to determine the load at which the concrete members may crack. The tension failure may occur in form of crack. In this test concrete specimen is applied to a compressive force in such a way that the specimen fails due to tensile stresses developed in the specimen. To determine the split tensile test, cylinder size of $300 \mathrm{~mm}$ height and $150 \mathrm{~mm}$ diameter has casted. Specimens were cured after the 24 hours of demoulding. The test was carried out for the partial mix specimens and control specimens. The chart is furnished to establish the results of comparison. 


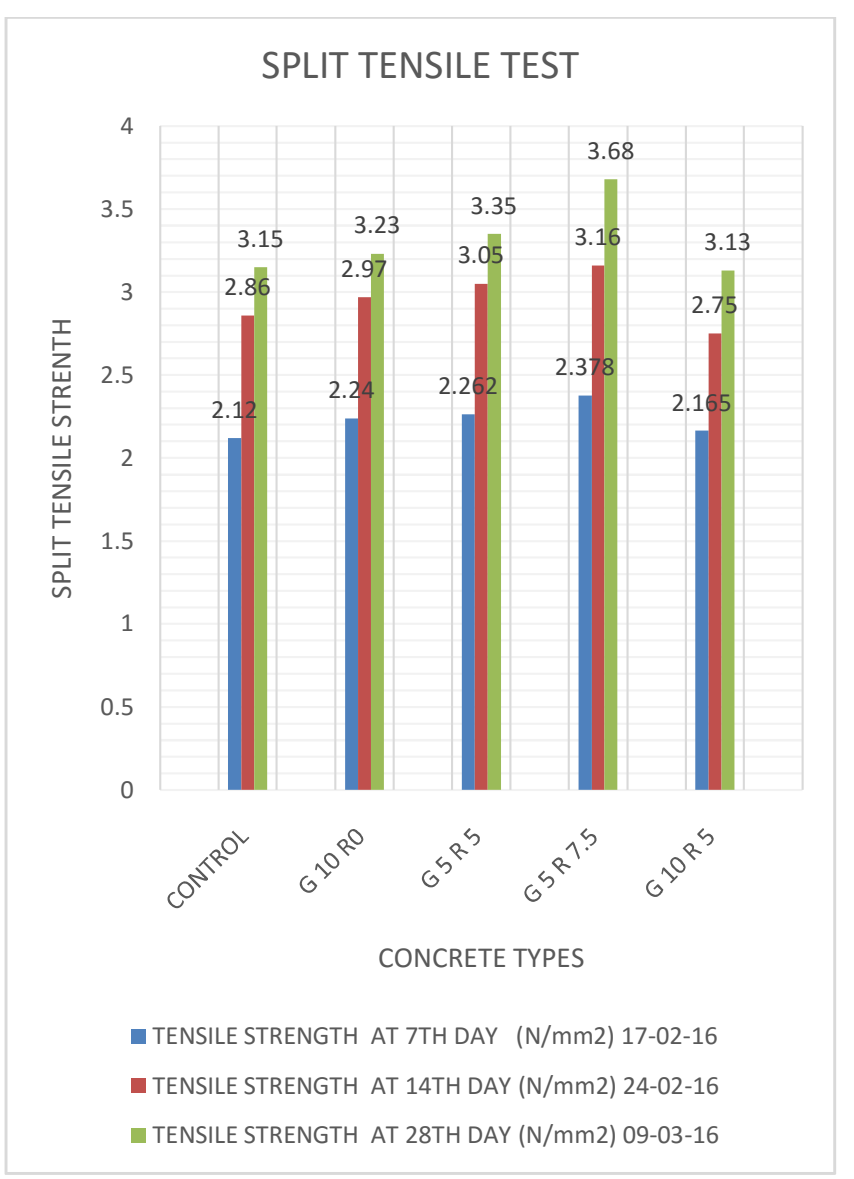

Chart-7 Comparison of tensile strength for partial mix specimens and control specimens.

\section{RESULTS AND DISCUSSIONS}

The several tests like slump cone test, compaction factor tests, compression test, flexural strength test, split tensile test were done on the different proportions of partial mix with variations of $5 \%, 10 \%, 15 \%$ of the waste glass powder with the fine aggregate and with the variations of $2.5 \%, 5$ $\%, 7.5 \%$ of the recycled aggregate with the coarse aggregate.

The hardened partial mix concrete were analyzed and compared with the tests reports of control concrete. By comparing the results of slump cone test value of partial mix to the control mix. $\mathrm{G}_{5} \mathrm{R}_{7.5}$ gives the highest slump value. While comparing the results of compaction factor test it gives peak value for the mix $G_{10} R_{0}, G_{5} R_{7.5}$. By comparing the results of hardened concrete tests, in compression test the $\mathrm{G}_{5} \mathrm{R}_{7.5}$ concrete specimen shows the peak compression strength of $34.5 \mathrm{~N} / \mathrm{mm}^{2}$. In flexural strength test $G_{5} R_{7.5}$ concrete specimen shows the peak tensile strength of 4.78 $\mathrm{N} / \mathrm{mm}^{2}$ and $\mathrm{G}_{5} \mathrm{R}_{5}$ concrete specimen shows the second peak tensile strength of $4.62 \mathrm{~N} / \mathrm{mm}^{2}$.In split tensile test $G_{5} R_{7.5}$ concrete specimen shows the peak tensile strength of 3.68 $\mathrm{N} / \mathrm{mm}^{2}$.

\section{CONCLUSION}

As a conclusion all the objectives of this study are achieved successfully. By the review of the results of various tests like slump cone test, compaction factor test, it is illustrated that $\mathrm{G}_{5} \mathrm{R}_{7.5}$ concrete mix has higher workability and by the review of the result of test like compression test the compression strength is good in concrete specimen $G_{5} R_{7.5}$. By the view of Split tensile and flexural strength test value it is concluded that $G_{5} R_{7.5}$ concrete mix specimens have better tensile properties than the control concrete specimens. Herewith it is concluded that they can be used for various construction purposes. Because it has higher workability than the traditional control concrete, good compression strength and usually concrete is weak in tensile strength but it gives tensile strength too.

\section{REFERENCES}

[1].Utilisation of Waste Glass Powder in Concrete- A Literature Review

1Bhupendra Singh Shekhawat2, Dr. VanitaAggarwal

MullanaAmbala, Haryana, IndiaProfessor, Department of Civil Engineering, MMEC, MMU, MullanaAmbala, Haryana, India

[2].Beaudoin J.J., and Feldman R. F., (1979), 'Partial replacement of cement by fly ash in autoclaved products theory and practice', International Journal of materialscience Vol. 14, pp. 1681-1693.

[3].Management and recycling of waste glass in concrete products: CurrentSituations in Hong Kong

Tung-Chai Ling, Chi-Sun Poon,Hau-Wing Wong

Department of Civil and Environmental Engineering, The Hong Kong Polytechnic University, Hung Hom, Kowloon, Hong Kong

[4].IS 383 (1970): Specification for Coarse and Fine Aggregates From Natural Sources For Concrete [CED 2: Cement and Concrete]

[5].IS 10262:2009, 'Concrete mix proportioning', Burea u of Indian Standards, New Delhi, India.

[6].IS 456:2000, 'Indian standard plain and Reinforced Concrete Code of Practice',Bureau of Indian Standards, New Delhi, India.

[7]. Sameer Shaikh et al. Int. Journal of Engineering Research and Applicationswww.ijera.com

ISSN: 2248-9622, Vol. 5, Issue 12, (Part - 4) December 2015, pp.01-04

[8].IS 1199 (1959): Methods of sampling and analysis of concrete [CED 2: Cement and Concrete]

[9].Madan Mohan Reddy.K, Bhavani.R, Ajitha. B / International Journal of Engineering Researchand Applications (IJERA) ISSN: 2248-9622 www.ijera.com Vol. 2, Issue 5, September- October 2012, pp.1236-1238. 